\title{
ZIRCONIUM TETRAIODIDE.
}

By L. M. DENNIS AND A. E. SPENCER.

Recelved June 9, 1896 .

WITH the exception of the tetraiodide all of the normal halides of zirconium have been prepared and described, the fluoride, chloride, and bromide being white, crystalline, sublimable solids.

A few attempts to make the iodide are recorded in the journals, but in no case was the normal compound, zirconium tetraiodide, $\mathrm{ZrI}_{4}$, obtained. Melliss ${ }^{1}$ passed the vapor of iodine over a glowing mixture of zirconia and carbon; he also treated zirconium tetrabromide with potassium iodide, but in neither case did zirconium tetrachloride result. Hinsberg ${ }^{2}$ added an aqueous solution of barium iodide to a solution of zirconium sulphate, filtered off the barium sulphate, and evaporated the filtrate over concentrated sulphuric acid. He obtained a compound of the formula $\mathrm{Zr}_{2} \mathrm{I}_{3} \mathrm{O}_{3}$, or $\mathrm{ZrI}(\mathrm{OH})_{3}$. He also passed the vapor of iodine over a heated mixture of zirconium dioxide and carbon and states that no reaction whatever took place. Bailey ${ }^{3}$ states that "zirconium" is acted upon by chloriue and bromine, in which, on gentle heating, it undergoes vivid combustion, forming the tetrahaloid derivatives, and this is, indeed, a convenient method for obtaining these bodies. The iodide could not be obtained."

In the work here to be described, the authors first attempted to prepare zirconium tetraiodide by passing the vapor of iodine over heated zirconium. The zirconium first used was made by reducing zirconium dioxide with magnesium powder, the two substances being mixed in the proportion employed by Winkler" and demanded by the equation

$$
\mathrm{ZrO}_{2}+2 \mathrm{Mg}=\mathrm{Zr}+2 \mathrm{MgO} \text {. }
$$

This mixture was heated in hydrogen in the usual manner and the resulting black powder was removed from the boat, thoroughly ground, and again heated in hydrogen to insure

\footnotetext{
1 Ztschr. Chem., 1870, 296: Jsb., $7870,328$.

2 Ann. Chem, (Liebig), 239, 253.

8 Chem News., 60, 8.

4 Prepared by the reduction of zirconia with magnesium powder.

5 Ber. d. chem. Ges., 23, 2664; 24, 888.
} 
conplete reduction. To free it from magnesia, the product was treated with a saturated solution of ammonium chloride. During this treatment a gas of very disagreeable odor was evolved. It is dotubtless similar to that observed by Winkler at this point. The powder was then warmed with dilute twelve per cent. hydrochloric acid and, after collecting it on a filter, it was washed with water containing hydrochloric acid, then with alcohol and ether, and finally was dried in a current of hydrogen. The analysis gave

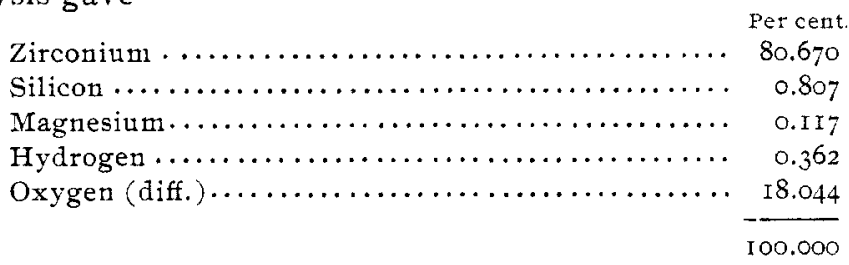

These results agree quite closely with those obtained by Winkler, ' and indicate that the product of the reduction is chiefly zirconium monoxide rather than zirconium.

Although the powder probably contained but very little free zirconium, it was nevertheless heated in hydrogen and vapor of iodine was passed over it. An examination of the product gave no satisfactory indications, however, that an iodide of zirconium had been formed.

Inasmuch as the failure to obtain union between the zirconium and iodine might reasonably be ascribed to absence of free zirconium in the above product, it seemed advisable, before attempting any modification of the iodine treatment, to prepare zirconium by some other method and especially by some procedure in which the presence of any appreciable amount of oxygen is avoided. Under the circumstances the method of Berzelius, ${ }^{2}$ the reduction of potassium fuozirconate with metallic potassium, seemed the most promising and was therefore employed.

The potassium fluozirconate was prepared from ircon. The zircon was finely ground, sifted through bolting cloth, and digested with concentrated hydrochloric acid until the acid gave

1 Ber, d. chem. Ges, 23, 2667.

2 Ann. der Phys. (Pogg), 4, II7. 
no reaction for iron. The powdered zircon, which was now almost perfectly white, was dried and mixed with four times its weight of sodium carbonate. The mixture was fused in an assay crucible furnace, allowed to cool, pulverized, and repeatedly extracted with water. The residue, consisting of zirconia and unattacked zircon together with some silica and ferric oxide, was heated with concentrated hydrochloric acid, evaporated to dryness, and heated in an air-bath to $120^{\circ}$ to render the silica insoluble. The dried mass was treated with a little hydrochloric acid, water was added, and the silica and other insoluble matter was filtered off. The filtrate, now containing zirconium chloride and some ferric chloride, was largely diluted with water, and ammonium hydroxide was added until there was formed a slight but permanent precipitate which was then dissolved by adding as little hydrochloric acid as possible. Sulphur dioxide was then passed into the solution until the liquid smelled strongly of the gas. In many cases a precipitate of basic zirconium sulphite formed at once, but, as the compound seemed to be somewhat soluble in an excess of sulphurous acid, the solution was always boiled for from ten to fifteen minutes to insure complete precipitation. In the reaction free hydrochloric acid is formed both by the conversion of the zirconium chloride into the basic sulphite and by the reductfon of the ferric chloride to the ferrous salt. As this acid would dissolve the zirconium sulphite, it was partially neutralized by the addition, from time to time, of a few drops of dilute ammonium hydroxide. The zirconium precipitate not being wholly free from iron, it was dissolved in hydrochloric acid and again precipitated with sulphur dioxide. The pure zirconium basic sulphite thus obtained was dissolved in hydrochloric acid and zirconium hydroxide was precipitated by adding ammonium hydroxide. The well-washed hydroxide was dissolved in hydrofluoric acid, potassium fluoride was added, and the resulting potassium fluozirconate was dissolved in hot water and recrystallized.

The potassium fluozirconate thus prepared was reduced with metallic sodium, the operation being carried out in a cast-iron crucible. The crucible is cylindrical in form with an internal diameter of two inches and depth of five inches. The wall and 
bottom are over one inch in thickness. At the top it has a flange seven inches in diameter and is provided with a cast-iron cover one inch in thickness, which can be firmly fastened to the flange by means of six one-half inch bolts.

In charging the crucible, sodium chloride, finely ground and thoroughly dried, was first put in to the depth of about an inch and a half, and this was then well pounded down with a wooden plunger to compact the salt and expel the enclosed air. On top of the salt were placed alternate layers of potassium fluozirconate, also thoroughly dried, and metallic sodium, these being pounded down as before. The remaining space in the crucible was then filled with sodium chloride and, after pounding this down, the top was bolted on and the crucible was heated for about three hours with three triple burners. This heat, however, was not sufficient to raise the crucible to redness.

The crucible was then allowed to cool and, upon opening it, the charge was found to be so compact that it had to be loosened with a chisel. On treating the mass with water the metallic zirconium, together with a small amount of the oxide which had formed, settled to the bottom while the sodium chloride and potassium and sodium fluorides dissolved.

The zirconium and zirconium oxide were separated by first floating off the lighter zirconium with water and then digesting it with dilute hydrochloric acid at $40^{\circ}$ until all of the oxide had been dissolved. The resulting product was a black, amorphous powder which, after washing with water, alcohol, and then with ether, showed no trace of impurity before the spectroscope except a slight amount of sodium.

Vapor of iodine was passed over some of this zirconium heated to dull redness in a current of hydrogen, but with no better success than with the other sample. We then concluded to substitute hydriodic acid gas for the iodine. Considerable difficulty was encountered in finding a suitable method of preparing the gaseous hydriodic acid. That described by Merz and Holzmann' was finally found to answer admirably. It consists in passing dry hydrogen and vapor of iodine through a red hot tube filled

1 Ber. a. chem. Ges., 22, 567. 
with pumice stone and freeing the hydriodic acid gas from iodine by passing the gases through cotton.

In treating the zirconium with hydriodic acid gas the following apparatus was used.

Iodine was placed in a small tubulated flask connected on one side with an apparatus furnishing pure, dry hydrogen and on the other side with a long piece of combustion tubing. The half of this tube nearest the iodine flask was filled with pieces of pumice stone and rested in a combustion furnace. The other half, extending beyond the combustion furnace, was flled with cotton. The end of this tube was connected with another combustion tube resting in a second combustion furnace. The porcelain boat containing the zirconium was placed in this second tube.

The hydrogen was first passed through the whole apparatus for several hours and then the first furnace was lighted. When the pumice had become red hot the flask containing the iodine was gently heated. The tube containing the zirconium soon became filled with the hydriodic acid gas, whereupon the second furnace was lighted. As the temperature rose, a brownish-yellow substance collected in the cold end of the combustion tube, but as the heat became greater the color entirely disappeared and there remained an amorphous white sublimate. No further sublimate was formed until the tube had almost reached a bright red heat when there appeared iust beyond the point where the tube was red hot a white crystalline sublimate, different in appearance from that which first formed. The gas escaping from the end of the tube contained hydriodic acid, hydrogen, some iodine, and a trace of iron, the last probably being present in traces in the zirconium and volatilizing as ferrous iodide. The tube was kept at a bright red heat for from three to four hours. The gas was then turned off and when the boat had cooled considerably the heating of the iodine flask was discontinued. The first furnace was then shut off and the whole apparatus was allowed to cool in the current of hydrogen.

The material in the boat had changed from a black to a grayish-white color, but a chemical examination showed that it contained very little iodine. The amorphous sublimate which first 
formed was found not to be zirconium iodide but to contain chiefly iron and iodine.

The crystalline sublimate which was formed only at a red heat was next analyzed. These crystals were found to be insoluble in water, nitric acid, hydrochloric acid, aqua regia, and carbon disulphide. They were decomposed and dissolved by concentrated sulphuric acid; they were also decomposed, but not completely, by concentrated nitric acid, iodine being liberated and a white powder, insoluble in the nitric acid, remaining. This residue was soluble in concentrated sulphuric acid and from this solution ammonium hydroxide threw down a white gelatinous precipitate. Upon dissolving this precipitate in hydrochloric acid and dipping turmeric paper into the solution, the orange color characteristic of zirconium was obtained. The solution gave no reaction for iron.

The zirconium in the compound was quantitatively determined by expelling the iodine by heating a portion of the salt with a mixture of sulphuric, nitric, and nitrous acids, dissolving the residue in concentrated sulphuric acid, diluting with water, and precipitating the zirconium with ammonium hydroxide. The precipitate was washed, dried, and ignited, and the zirco. nium weighed as the dioxide.

The iodine was determined by fusing some of the compound with about five times its weight of a mixture of potassium and sodium carbonate. The mass was then treated with water, filtered, and after acidifying the filtrate with nitric acid the hydriodic acid was precipitated with silver nitrate and weighed as silver iodide.

The results were

\begin{tabular}{|c|c|c|c|c|}
\hline & $\begin{array}{c}\text { Calculated for } \mathrm{ZTI}_{4} \\
\text { Per cent. }\end{array}$ & Per cent. & $\begin{array}{l}\text { Found. } \\
\text { Per cett. }\end{array}$ & Per cent. \\
\hline Zirconiun & I 5.15 & I 5.17 & 15.00 & I $5 \cdot 37$ \\
\hline Iodine ... & 84.85 & 85.34 & 85.27 & $\ldots$ \\
\hline
\end{tabular}

The crystals when examined under the microscope proved to be clear, colorless cubes which showed no double refraction.

When heated for some hours in hydrogen the zirconium tetraiodide becomes black and iodine and hydriodic acid are formed. Heated in the air the iodide melts and sublimes. A weighed amount was placed in a porcelain crucible, covered with water, 
and evaporated to dryness. No change in weight and scarcely any in color resulted after two such treatments. This behavior toward water is surprising, for from the published descriptions of zirconium tetrachloride and tetrabromide, it was to be expected that the iodide would prove to be a hygroscopic compound easily decomposed by water. It seems, however, to more nearly resemble the fluoride which Deville states to be a colorless crystalline substance volatile at a white heat and insoluble in water or acids.

CORNELL UNIVERSTTY, ITHACA, N. Y.

\section{PHTHALIMID. ${ }^{1}$}

\section{BY J. A. MatheWS}

Received Juse 9, 1896.

A NUMBER of years ago Prof. C. E. Colby and Mr. Dodge, $A$ of Columbia University were led to try the effect produced by heating together, under pressure, mixtures of ( 1 ) fatty acids and fatty nitrils; (2) fatty acids and aromatic nitrils; (3) fatty nitrils and aromatic acids; and (4) aromatic acids and aromatic nitrils. The reactions were carried on in sealed tubes. The score or more reactions that they tried were done at temperatures ranging from $235^{\circ}$ to $280^{\circ} \mathrm{C}$. As the result of their work they reached these conclusions regarding what is likely to take place, at least when monobasic acids and mononitrils are employed."

I. Fatty nitrils and fatty acids give secondary amids.

2. Fatty nitrils and aromatic acids give fatty acids and aromatic nitrils.

3. Aromatic nitrils and fatty acids give mixed secondary amids.

4. Aromatic nitrils and aromatic acids gave secondary amids, except in one case when exceptionally high heat was used $\left(280^{\circ}\right)$ in which case the cyanide of the higher radicle was formed.

In regard to dibasic acids and dicyanides not so much has been done. Miller first tried reactions with succinic acid and ethylene cyanide. ${ }^{3} \mathrm{He}$ found that succinimid resulted from each of the following experiments :

1 Read before the American Chemical Society. New York Section, June, I 896.

$2 \mathrm{Am}$. Chem. J., I3, $189 \mathrm{l}$.

8 This Journal, $I 6,443,7894$. 